\title{
Development of the Prefrontal Cortex during Adolescence: Insights into Vulnerable Neural Circuits in Schizophrenia
}

\author{
David A. Lewis, M.D.
}

Multiple lines of evidence suggest that the prefrontal cortex is a site of dysfunction in schizophrenia. In addition, one of the characteristics of this disorder is the tendency for clinical symptoms to appear first during late adolescence or early adulthood. Recent studies in nonhuman primates have shown that the connectivity of the prefrontal cortex is substantially refined during adolescence, suggesting that these developmental changes may be critical for the appearance of the clinical features of schizophrenia. This article reviews data demonstrating that these late developmental changes are selective for particular neural elements in the prefrontal cortex and that they are synaptically linked. It is suggested that these neural elements comprise a functional circuit that is likely to be especially vulnerable in schizophrenia, a hypothesis that can be directly tested in postmortem studies.

[Neuropsychopharmacology 16, 385-398, 1997] (C) 1997 American College of Neuropsychopharmacology
KEY WORDS: Cortical development; Dopamine; Local circuit neurons; Prefrontal cortex; Pyramidal neurons;

Schizophrenia

The symptoms of schizophrenia appear to be associated with dysfunction and structural changes in a number of brain regions, as well as in the connections that link these regions (see Friston and Frith 1995; Pearlson et al. 1996 for review). Understanding the pathophysiology of this disorder will ultimately require an appreciation of how abnormalities in one brain region produce and/ or result from disturbances in other brain areas. However, knowledge of the circuitry abnormalities within an affected region is a critical step in this process as the output from a given region is dependent on the flow of information processing within that region.

Multiple lines of evidence suggest that the dorsolateral prefrontal cortex (DLPFC) is a site of dysfunction in

From the Departments of Psychiatry and Neuroscience, University of Pittsburgh, Pittsburgh, Pennsylvania.

Address correspondence to: David A. Lewis, M.D., BST W1650, Western Psychiatric Institute and Clinic, University of Pittsburgh, 3811 O'Hara Street, Pittsburgh, Pennsylvania 15213.

Received September 10, 1996; accepted November 26, 1996. schizophrenia (Levin 1984; Weinberger et al. 1986; Park and Holzman 1992), although controversy exists regarding the interpretation of some findings (Chua and McKenna 1995; Gur and Gur 1995). The results of recent in vivo imaging and postmortem studies suggest that DLPFC dysfunction may be related to alterations in the synaptic connectivity of this region. For example, prefrontal cortex (PFC) gray matter volume has been found to be decreased in schizophrenic subjects in some (Shelton et al. 1988; Breier et al. 1992; Zipursky et al. 1992; Andreasen et al. 1994b; Schlaepfer et al. 1994), but not all (Wible et al. 1995) MRI structural studies, and MRI spectroscopic investigations have found evidence for a decrease in synaptic building blocks in the DLPFC (Pettegrew et al. 1991; Stanley et al. 1995). Similarly, postmortem studies have found that cell-packing density is increased and cortical thickness decreased in the DLPFC of schizophrenic subjects (Pakkenberg 1987; Daviss and Lewis 1995; Selemon et al. 1995). In addition, the total number of cortical neurons does not appear to be altered in schizophrenia (Pakkenberg 1993; Akbarian et al. 1995), although some investigators have observed decreased numbers of certain populations of 
prefrontal neurons (Benes et al. 1991). Together, the presence of increased cell packing density without a change in neuron number suggests that the DLPFC neuropil, which includes the axon terminals, small dendrites, and dendritic spines that are the components of most cortical synapses, is diminished in schizophrenia. Consistent with this interpretation, levels of the synapse-associated protein synaptophysin have been reported to be decreased in the DLPFC of schizophrenic subjects (Karson et al. 1996; Glantz and Lewis in press; Perrone-Bizzozero et al. 1996). However, understanding the potential etiological and pathophysiological significance of these apparent alterations in synaptic connectivity requires an understanding of which elements of DLPFC circuitry are preferentially affected.

Given the accumulating evidence that schizophrenia is a neurodevelopmental disorder (Waddington 1993), one approach for identifying these vulnerable neural elements involves studies of the normal maturation of the functional architecture of the DLPFC. Indeed, one of the characteristics of schizophrenia is the tendency for clinical symptoms to first appear during late adolescence or early childhood, and it has been suggested that any hypothesis regarding the pathophysiology of schizophrenia must account for this age of onset (Feinberg 1982; Weinberger 1987). Recent findings indicate that the primary pathological event in at least some cases of schizophrenia may occur during the pre- or perinatal periods (Benes 1991; Murray et al. 1992; Pilowsky et al. 1993), with the functional consequences of such developmental disturbances not clearly evident until the affected neural networks become fully mature after puberty (Weinberger 1987). In contrast, other investigators have proposed that schizophrenia is due to a disturbance in late developmental processes that occur during adolescence (Feinberg 1982; Hoffman and Dobscha 1989). Although the available data are inadequate to reject or accept either hypothesis, both converge on a common view that late developmental processes are critical to the pathogenesis of schizophrenia.

Interestingly, studies in both humans and nonhuman primates indicate that the DLPFC does not become functionally mature until after puberty. Consequently, understanding how the neural circuitry of the DLPFC is refined during adolescence may provide insights into which elements of this circuitry are disrupted in schizophrenia. Although the average age of first hospitalization for schizophrenic patients is in the early or midtwenties for males and females, respectively (Castle and Murray 1991; Szymanski et al. 1995), psychotic symptoms may appear months or even years prior to hospitalization (Haas and Sweeney 1992; Larsen et al. 1996; Szymanski et al. 1995). In addition, deterioration in other areas that may be more directly dependent on the functional integrity of the DLPFC, such as scholastic performance and sociability, precedes the onset of the overt symptoms of schizophrenia by some time (Haas and Sweeney 1992; Larsen et al. 1996). Thus, developmental events occurring during the second decade of life may play a critical role in the appearance of DLPFC dysfunction in schizophrenia.

The following sections review recent studies on the normal development of the primate DLPFC during adolescence. Based on these findings, I propose a provisional, but testable, model of a specific set of synaptically linked components of DLPFC circuitry that is altered in schizophrenia. This model, presented as a circuitry diagram in Figure 1, represents an extension and refinement of one presented in an earlier publication (Lewis and Anderson 1995).

\section{FUNCTIONAL MATURATION OF DLPFC CIRCUITRY}

In both monkeys and humans, the functional maturation of the DLPFC appears to be quite protracted. For example, cerebral blood flow in the frontal cortex does not reach adult patterns in humans until 15 to 19 years of age (Chugani et al. 1987; Chiron et al. 1992), and adult levels of performance on some cognitive tasks mediated by the DLPFC are not achieved until after puberty in both monkeys and humans (see later). Together, these findings suggest that critical changes in the organization of the DLPFC may be occurring during the peripubertal or adolescent period of development. In this article, peripubertal and adolescent are used interchangeably to refer to the period of development that begins just prior to the onset of puberty and concludes when all features characteristic of adulthood are achieved. Chronologically, the peripubertal or adolescent period corresponds roughly to the second decade of life in humans and to the age range of two to four years in macaque monkeys. As will become evident in the following sections, the relatively small numbers of both monkey and human subjects that have been included in most studies conducted to date preclude the identification of more precise epochs within this interval of development.

One of the cardinal behaviors subserved by the DLPFC in adults is the performance of delayed-response tasks (Fuster 1989). These tasks, some versions of which can be performed by both monkeys and humans, require the subject briefly to retain knowledge of the information provided by a sensory cue in order to produce the appropriate behavioral response following the removal of that cue. For example, in oculomotor delayedresponse tasks, subjects are required to hold "on line" or in "working memory" the location of a visual stimulus in space during a delay period when the stimulus is absent (Goldman-Rakic 1987a). The ability to carry out such tasks first appears between two and four months 
of age in monkeys (Goldman-Rakic 1987b) and around one year of age in humans (Diamond 1985, 1990). Performance on these tasks then continues to improve at a slower rate until adult functional competence is achieved following puberty in both monkeys (Alexander and Goldman 1978; Goldman 1971) and humans (Levin et al. 1991).

The time course of improved performance with age, as evidenced by the ability to withstand longer delay periods, appears to reflect not only the functional maturation of the DLPFC, but also the increasing involvement during postnatal development of DLPFC circuitry in the mediation of these behaviors. That is, the emergence of the ability to perform delayed-response tasks during infancy does not appear to depend on the integ- rity of the DLPFC and consequently is mediated by other neural circuitry. For example, ablation of the DLPFC in infant monkeys does not produce the same degree of impairment on spatial delayed-response tasks observed in adult animals with such lesions (Alexander and Goldman 1978). In contrast, during the first year of life, these behaviors do appear to depend on the integrity of other brain structures, including the caudate nucleus (Goldman and Rosvold 1972), mediodorsal thalamic nucleus (Goldman 1974; Alexander and Goldman 1978), and orbitofrontal cortex (Goldman 1971; Miller et al. 1973).

Studies that have employed reversible cooling of the DLPFC, which temporarily disrupts neural activity in the affected area, also have demonstrated an age-dependent

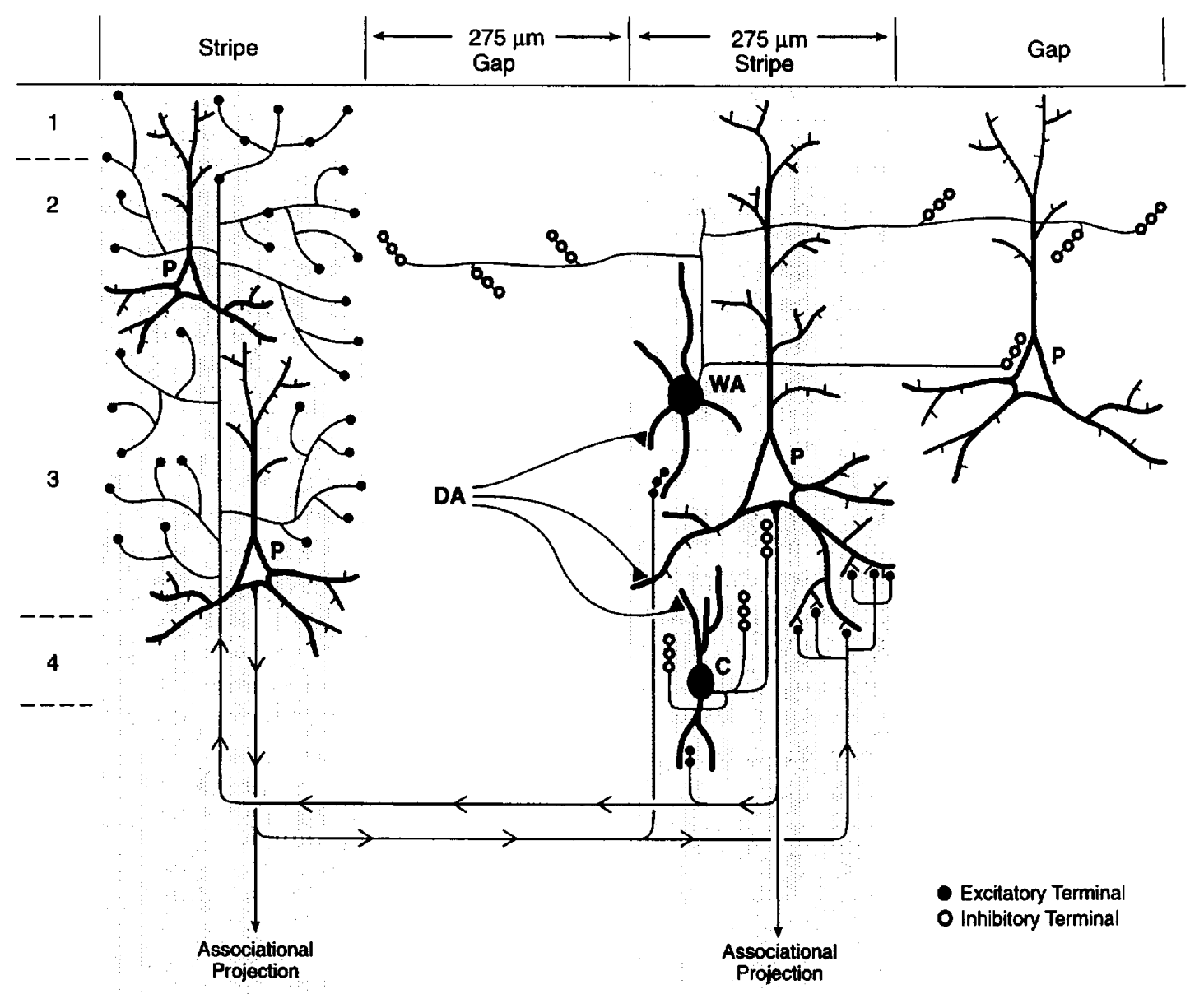

Figure 1. Connectivity in the supragranular layers of monkey DLPFC. Layer 3 pyramidal neurons (P) furnish horizontal axon collaterals that terminate in stripelike arrays (approximately $275 \mu \mathrm{m}$ wide by $1,800 \mu \mathrm{m}$ long) in the superficial cortical layers. These excitatory axon terminals (solid circles) target dendritic spines, many of which may belong to the pyramidal neurons that provide reciprocal connections between stripes. These excitatory axon terminals also target the dendrites of GABA local circuit neurons that may include the wide arbor (WA) subclass. As shown, wide arbor neurons appear to be specialized to provide inhibitory input to the soma of pyramidal neurons located in the "gaps" of a given network of intrinsic stripes. In contrast, chandelier neurons $(C)$ within a given stripe are thought to furnish inhibitory input to the axon initial segment of pyramidal neurons located within the same stripe (open circles, inhibitory terminals). Dopamine (DA) afferents to the middle cortical layers synapse on the dendritic spines and shafts of pyramidal neurons and on the dendrites of parvalbumin-containing local circuit neurons that may include wide arbor and/or chandelier neurons. See text for additional details. 
role of the DLPFC in certain behaviors (Alexander and Goldman 1978; Alexander 1982). In these studies, cooling of the DLPFC did not produce impairments in delayed-response performance in monkeys 9 to 16 months of age. In animals 19 to 31 months old, cooling produced a modest degree of disruption in task performance compared to pre- and post-cooling conditions. However, in animals 3 years of age, the typical age of puberty in this species, cooling of the DLPFC resulted in a substantial impairment of performance. These findings suggest that during postnatal development, delayed-response behavior becomes increasingly dependent on the DLPFC and that the maturation of the DLPFC augments the function of neural circuits that appear to subserve the same task earlier in life (Alexander and Goldman 1978). Consequently, the improvement in performance on delayed-response tasks with age may reflect both the maturation of the functional architecture of the DLPFC and its increased participation in the neural circuits that mediate these types of cognitive abilities.

Further evidence for the increasing involvement of DLPFC circuitry in delayed-response tasks during postnatal development has been derived from electrophysiological studies of this region. In adult animals, specific populations of DLPFC neurons have been identified whose activity is temporally linked to specific components of the delayed-response task (Fuster et al. 1982). In particular, some DLPFC neurons exhibit elevated firing rates during the delay period of the task, and the loss of this delay-related neuronal activity is associated with errors in the performance of the task (Bauer and Fuster 1976; Funahashi et al. 1989). During postnatal development, the percentage of DLPFC neurons that exhibit delay period activity doubles between 12 and 36 months of age, suggesting that developmental changes in DLPFC circuitry facilitate the recruitment of these neurons to this functional role (Alexander 1982). However, in contrast to other brain areas (e.g., mediodorsal thalamic nucleus, caudate nucleus, posterior parietal cortex) that also subserve delayed-response tasks, only the DLPFC appears to exhibit this type of developmental increase in the number of delay-activated neurons (Alexander 1982).

\section{NEURAL SUBSTRATE FOR SUSTAINED NEURONAL ACTIVITY IN DELAYED-RESPONSE TASKS}

Given this temporal pattern of DLPFC functional maturation, understanding the neural substrate for the sustained activity of DLPFC neurons during the delay period of delayed-response tasks may suggest which components of DLPFC circuitry undergo late developmental refinements. In addition, as schizophrenic sub- jects perform poorly on the oculomotor delayed-response task (Park and Holzman 1992), exhibiting deficits similar to those seen in monkeys with lesions of the DLPFC, this knowledge may provide clues as to the elements of DLPFC circuitry that exhibit altered connectivity in schizophrenia. Pyramidal neurons, the major class of excitatory cortical neurons, are of particular interest in this regard. In the supragranular layers (layers 2 and 3 ) of the primate $\mathrm{PFC}$, pyramidal neurons furnish principal axon projections to other cortical regions. (Schwartz and Goldman-Rakic 1984; Barbas and Pandya 1989; Pucak et al. 1996). In addition, intrinsic axon collaterals from these pyramidal cells extend for considerable distances horizontally through the gray matter and give rise to clusters of axon terminals in the superficial cortical layers, which are organized as a series of stripes (Levitt et al. 1993). These stripes are, on average, 275 $\mu \mathrm{m}$ wide and $1.8 \mathrm{~mm}$ long and are separated by gaps of similar size (Pucak et al. 1996). The pyramidal neurons that give rise to these intrinsic axon collaterals are also organized as stripes (Kritzer and Goldman-Rakic 1995; Pucak et al. 1996), and combinations of anterograde and retrograde tracing studies indicate that reciprocal connections are present among these stripes (Pucak et al. 1996). In addition, ultrastructural investigations have shown that over $90 \%$ of the synapses furnished by these collaterals target the dendritic spines of other pyramidal cells (Melchitzky et al. 1995). As indicated in Figure 1 , these findings suggest that the intrinsic axon collaterals of supragranular pyramidal neurons may provide monosynaptic excitatory connections among pyramidal neurons located in interconnected stripes. Thus, these connections could provide the substrate for a reverberating cortical circuit that coordinates and maintains the activity of spatially segregated, but functionally-related, populations of DLPFC pyramidal neurons during the delay phase of delayed-response tasks (Lewis and Anderson 1995). Consistent with this interpretation, glucose utilization was found to be greatest in layer 3 of the DLPFC in monkeys that had been performing a spatial-delayed response task (Friedman and GoldmanRakic 1994).

The remaining synapses furnished by these intrinsic axon collaterals provide excitatory input to the dendrites of local circuit neurons (Melchitzky et al. 1995) that most likely utilize the inhibitory neurotransmitter GABA. It has been suggested (Levitt et al. 1993; Lund et al. 1993) that at least some of this input to local circuit neurons may be directed at wide arbor cells (Lund and Lewis 1993), a subclass of GABA neurons that contain the calcium-binding protein parvalbumin (Condé et al. 1994) and that provide inhibitory input to the cell body of pyramidal neurons (Williams et al. 1992). Although the dendritic field width of these neurons (approximately $300 \mu \mathrm{m}$; Lund and Lewis 1993) suggests that their afferent drive is limited to axon terminals within a 
stripe, the size and spatial organization of their axonal arbors appear to be specialized for targeting the pyramidal neurons located in the gaps between sets of interconnected stripes (Figure 1). Consequently, activation of a given stripelike cluster(s) of supragranular pyramidal neurons may lead to sustained firing in the pyramidal neurons distributed across an assembly of interconnected stripes and suppression of firing in the pyramidal neurons located in the intervening areas, helping to maintain the fidelity of the information content coded by the activity in the interconnected stripes. Although this hypothesis is speculative and awaits support from empirical physiological studies, it points to the potential importance of supragranular pyramidal neurons in the performance of delayed-response tasks and, consequently, in the pathophysiology of schizophrenia.

\section{DEVELOPMENTAL CHANGES IN DLPFC SYNAPSES}

The potential significance of these supragranular pyramidal neurons is further indicated by evidence that critical shifts in synaptic input to these neurons occurs during adolescence. In the neuropil of both monkey and human DLPFC, synaptic density increases during early postnatal development, remains at a stable plateau for an extended period, and then declines during adolescence (Huttenlocher 1979; Bourgeois et al. 1994). Embedded within these changes in the overall density of DLPFC synapses are additional patterns of change that are specific to different types of synapses. For example, in monkey DLPFC the density of synapses on dendritic shafts peaks at around 2 months after birth, and this level appears to be maintained throughout the life span. These synapses account for $25 \%$ to $40 \%$ of all synapses, and in terms of total number, they do not appear to be overproduced or pruned. In contrast, synapses on the dendritic spines of pyramidal neurons appear to contribute to most or all of the transient overproduction of DLPFC synapses. These synapses decline in density by $50 \%$ in monkeys over 3 years old (Bourgeois et al. 1994), the typical age of puberty in this species (Plant 1988).

Although these overall patterns of postnatal change in synaptic density are similar in all regions of primate cortex studied (Rakic et al. 1986), regional, laminar, and cellular differences in the precise time course of these changes have been observed. For example, in layer 3 of the human cerebral cortex, total synaptic density peaks at 6 months of age in the primary visual cortex (Huttenlocher and DeCourten 1987), but at 2 years of age in the prefrontal regions (Huttenlocher 1979). Laminar differences in the temporal pattern of postnatal synaptic production and elimination also have been described in several regions of the monkey neocortex. In the primary visual cortex, Bourgeois and Rakic (1993) found that the periods of overshoot and regression in the density of synapses in layer 4 were completed prior to 1 year of age, whereas in both the superficial and deep layers of this region the plateau phase of relatively high synaptic density persisted into the third year of life. In addition, within monkey DLPFC the early overshoot and peripubertal reduction in synaptic density was more pronounced in the supragranular than in the infragranular layers (Bourgeois et al. 1994). Within a cortical layer, separate classes of neurons may also differ substantially in the timing of synaptic production and elimination. For example, in layer 4 of the monkey primary visual cortex, changes in the densities of dendritic spines (markers of sites of excitatory synapses) on the alpha and beta types of spiny stellate cells follow markedly different time courses during the first 6 months of life (Lund and Holbach 1991).

Overall, the time course of synaptic development strongly suggests that the connectivity of the primate DLPFC undergoes substantial changes during adolescence. However, because of the apparent regional, laminar, and cellular specificity in the timing and magnitude of maturational changes in cortical synaptic density, it is important to determine how specific and interrelated components of DLPFC circuitry change during postnatal development, particularly those involving supragranular layer 3 pyramidal neurons. The vast majority of asymmetric, excitatory synaptic inputs to pyramidal neurons are located on dendritic spines (Colonnier 1968; LeVay 1973; Mates and Lund 1983; Saint Marie and Peters 1985), and changes in spine number appear to reflect parallel changes in excitatory inputs to these neurons (Lund and Holbach 1991). In Golgi studies (Anderson et al. 1995), the density of dendritic spines on layer 3 pyramidal neurons of monkey DLPFC was found to undergo substantial changes during postnatal development. The dendrites of these neurons exhibited a rapid acquisition of spines between birth and 10 weeks of age (Figure 2). They then maintained a high density of spines at a relatively constant value, approximately $50 \%$ higher than at birth, over a period of at least 14 months. Based on studies in other neuronal systems (Changeux and Danchin 1976; Purves and Lichtman 1980), the temporary maintenance of these high levels of excitatory inputs to pyramidal neurons may be necessary for appropriate competition among, and ultimately for the proper refinement of, cortical connections. After 1.5 years of age, layer 3 pyramidal neurons then underwent overall spine attrition, again by about $50 \%$, until adult levels were achieved by 4.5 years of age. Spine density then appeared to remain stable at these levels at least through 16 years of age. The time course for this acquisition and loss of spines during development was similar on both the apical and basilar dendritic trees of these neurons. Although pyra- 
midal neurons in the deep cortical layers were not examined in this study, other studies have shown that synaptic density in the supragranular layers of monkey DLPFC follows a different temporal pattern of overproduction and elimination than in the infragranular layers (Bourgeois et al. 1994), suggesting that the peripubertal elimination of DLPFC axospinous synapses and dendritic spines may particularly affect the connectivity of supragranular pyramidal neurons.

As indicated, over $90 \%$ of the synapses formed by the horizontally projecting axon collaterals of supragranular pyramidal neurons target the dendritic spines of other pyramidal cells (Melchitzky et al. 1995), raising the possibility that the peripubertal attrition of dendritic spines and axospinous synapses might be accompanied by a pruning of these intrinsic axon collaterals. Analysis of the patterns of anterograde labeling resulting from injections of biotinylated dextran amine in the superficial layers of the DLPFC in prepubertal monkeys revealed that the discrete stripelike organization of intrinsic axon terminals was already established (Woo et al. in press). However, the average area under the cortical surface occupied by each stripe was $50 \%$ greater than in adult animals, and the size of the "gaps" between stripes also was correspondingly smaller in the juvenile animals. In addition, quantification of varicosity density and the degree of arborization of labeled axons within stripes revealed that both of these measures decreased by about $50 \%$ from prepubertal to adult animals. Thus the substantial reduction in the amount of excitatory input to supragranular pyramidal neurons during puberty may be a consequence of the pruning of the intrinsic axon collaterals that interconnect spatially segregated, stripelike clusters of neurons. If, as suggested, these reciprocal intrinsic connections do subserve the sustained neuronal activity required for working memory, then this prepubertal pruning may sharpen the patterns of connectivity required for adult levels of per- formance. Furthermore, these intrinsic axon collaterals may be selectively, or at least preferentially, pruned during puberty. For example, about $70 \%$ of callosal axons are eliminated during the first 3 postnatal months (LaMantia and Rakic 1990), with the number remaining stable thereafter, suggesting that these axons may be less likely to be involved in the peripubertal attrition of DLPFC excitatory synapses. In addition, the size of the stripelike fields formed by the axon terminals that furnish intrahemispheric associational projections between different regions of the DLPFC does not change during puberty, and late developmental changes in the density of axonal varicosities are more limited for associational than intrinsic projections (Woo et al. in press).

\section{TEMPORALLY ASSOCIATED REFINEMENTS IN SYNAPTICALLY LINKED COMPONENTS OF DLPFC CIRCUITRY}

To summarize, during adolescence the number of axospinous synapses in the primate DLPFC appears to decline preferentially in the supragranular layers, to affect predominantly the excitatory input to pyramidal neurons located in these layers, and to be associated with a decrease in the number of intrinsic connections furnished by the axon collaterals of these neurons. Together, these findings suggest that the excitatory connections linking spatially segregated populations of pyramidal neurons in the supragranular layers of the DLPFC are substantially refined during adolescence. They also raise the question of whether similar developmental changes are seen in other types of inputs to these pyramidal neurons. For example, the chandelier class of local circuit GABA neurons provides an important source of inhibitory regulation of pyramidal regions. The axon terminals of chandelier neurons are arrayed as morphologically dis-

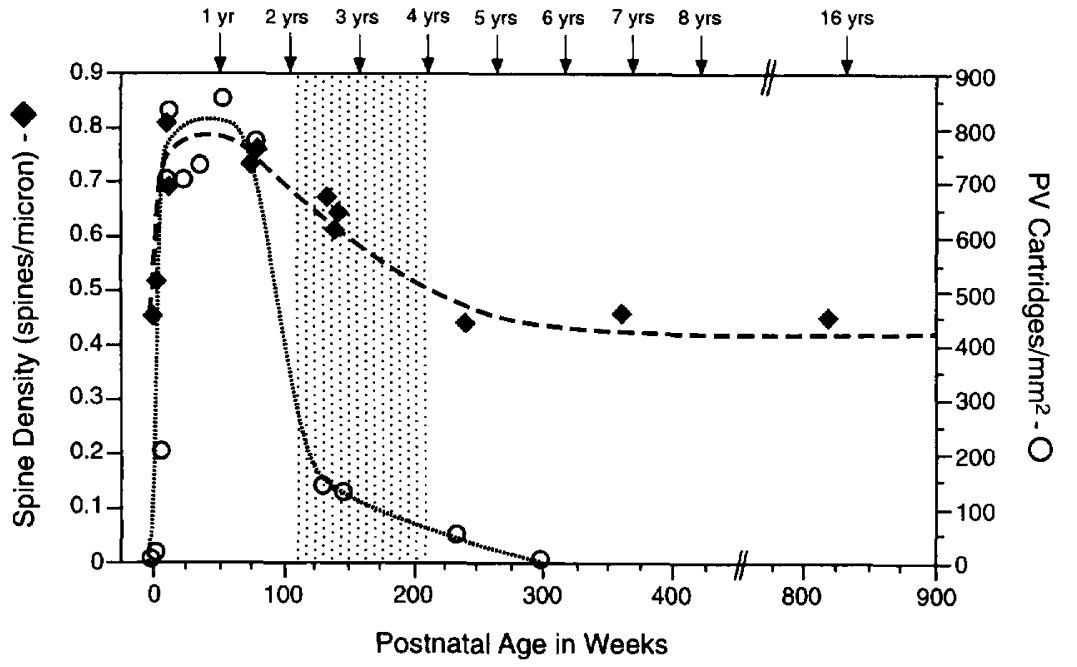

Figure 2. Age-related changes in the mean densities of spines on the dendrites of layer 3 pyramidal neurons (solid diamonds) and of parvalbumin (PV)-containing chandelier neuron axon cartridges (open circles) in monkey DLPFC. Note the parallel time course of developmental changes in these markers of excitatory and inhibitory inputs to layer 3 pyramidal neurons. Adapted from Anderson et al. 1995. 
tinct cartridges that form symmetric, inhibitory synapses on the axon initial segment of pyramidal neurons (Szentagothai and Arbib 1974; Jones 1975; Somogyi 1977; DeFelipe et al. 1985). These axon cartridges can be identified by the presence of the calcium-binding protein, parvalbumin (PV) (DeFelipe et al. 1989; Lewis and Lund 1990; Condé et al. 1994), and consequently the PV-immunoreactive axon cartridges of chandelier neurons located in layer 3 are likely to provide inhibitory input to layer 3 pyramidal neurons (Figure 1). Interestingly, the number of PV-positive axon cartridges in monkey DLPFC also undergoes substantial changes during postnatal development (Lewis and Lund 1990; Akil and Lewis 1992; Anderson et al. 1995). As shown in Figure 2, the density of PV-labeled cartridges increases rapidly during the first 3 months of postnatal development, undergoes a plateau period that lasts until at least 1.5 years of age, and then declines during the peripubertal age range to stable adult values (Anderson et al. 1995).

Although the change in density of PV-labeled axon cartridges could possibly be due to parallel developmental shifts in the number of chandelier neuron axon terminals or in the number of varicosities per cartridge, such changes have not been observed in Golgi studies of chandelier neurons in monkey DLPFC (Lewis and Lund 1990; Lund and Lewis 1993). For example, Golgiimpregnated chandelier neuron axon cartridges are clearly present in DLPFC layer 3 in both neonatal and adult monkeys; by contrast, in these same animals PVimmunoreactive cartridges are either not detectable or quite low in density (Lewis and Lund 1990). In addition, neither the number nor laminar distribution of PVpositive neurons in the DLPFC changes during adolescence (Condé et al. 1996). Thus, it seems likely that the observed changes in the number of PV-positive cartridges reflect developmental shifts in the level of PV immunoreactivity per cartridge.

Because levels of PV immunoreactivity appear to be correlated with neuronal activity (Heizmann 1984; Celio 1986; Kawaguchi 1995), the developmental changes in density of PV-immunoreactive cartridges may reflect the level of activity of the inhibitory synapses furnished by these axon terminals. Thus, during postnatal development, at least a subpopulation of chandelier neurons may vary their degree of inhibitory control over specific populations of pyramidal cells. The striking correlation across postnatal development (Figure 2) between the densities of PV-labeled cartridges in layer 3 and dendritic spines on layer 3 pyramidal neurons suggests that the strength of inhibitory inputs to these pyramidal neurons may change to match the strength of their excitatory inputs. Such a coordination between excitatory and inhibitory inputs could be achieved by the local axon collaterals (i.e., those that arborize within $150 \mu \mathrm{m}$ of the cell body) of layer 3 pyramidal cells contacting chandelier neurons (Figure 1), thus increasing or de- creasing the activity of the chandelier neurons in concert with changes in the excitatory inputs on the spines of those pyramidal neurons. Because chandelier neurons provide synaptic input to the axon initial segment, the site of action potential generation in pyramidal neurons, they exert potent inhibitory control over pyramidal neuron firing. Furthermore, because the width (250$300 \mu \mathrm{m}$ ) of the chandelier neuron axon arbor (Lund and Lewis 1993) is comparable to that of the stripes of supragranular pyramidal neurons, chandelier neurons in the middle cortical layers may be specialized for gating the output from a given stripe (Figure 1). Thus, given that each chandelier cell may innervate up to 300 pyramidal neurons (Peters 1984), only limited numbers of the synapses furnished by the local axon collaterals of layer 3 pyramidal neurons within a stripe would need to be directed at chandelier neurons. However, the existence of such a synaptic relationship between pyramidal neuron local axon collaterals and chandelier neurons in monkey DLPFC remains to be established.

The synchronous developmental changes in the density of dendritic spines and a marker of inhibitory inputs to layer 3 pyramidal neurons raise the question of whether these changes are linked to postnatal refinements in other elements of DLPFC circuitry. For example, the dopamine innervation of monkey DLPFC also undergoes substantial change during postnatal development (Goldman-Rakic and Brown 1982; Lewis and Harris 1991; Lidow et al. 1991; Rosenberg and Lewis 1995). Dopamine afferents to the primate DLPFC form symmetric contacts with dendritic spines and shafts of pyramidal neurons (Goldman-Rakic et al. 1989; Smiley et al. 1992), as well as with the dendrites of local circuit neurons (Smiley and Goldman-Rakic 1993) that contain GABA (Sesack et al. 1995b). In addition, among GABA neurons in the monkey DLPFC, the dendrites of PVcontaining cells in the middle cortical layers receive dopamine synaptic input (Sesack et al. submitted), whereas the calretinin-containing class of GABA neurons in the superficial layers do not (Sesack et al. 1995a). Consequently, the maturational changes in the dopamine innervation of DLPFC layer 3 are of particular interest (Figure 1). As summarized in Figure 3, the density of varicosities (possible sites of synaptic specializations or neurotransmitter release) on dopamine axons in layer 3 of monkey DLPFC increases during the first few postnatal months (Rosenberg and Lewis 1995), parallel to the increase in densities of pyramidal neuron dendritic spines and PV-immunoreactive chandelier neuron axon cartridges. After a plateau period, dopamine varicosities undergo a second marked increase in density to reach peak values between 2 and 3 years of age. The number of dopamine varicosities then rapidly declines to relatively stable adult levels by 5 years of age. This second rise in the density of dopamine varicosities appears to begin prior to the decline in the densities of py- 
ramidal neuron dendritic spines and PV-immunoreactive cartridges in layer 3 and to persist until the adult levels of these markers of excitatory and inhibitory inputs are achieved. These patterns suggest that the neuromodulatory effects of dopamine may influence the adolescent refinement of excitatory and inhibitory inputs to layer 3 pyramidal neurons and that dopamine may have a particularly strong influence on cortical information processing around the time of puberty. These findings also are of particular interest given the converging lines of evidence demonstrating that a certain range of dopamine input is critical for optimal performance of delayed-response tasks (Brozoski et al. 1979; Sawaguchi et al. 1986; Sawaguchi and Goldman-Rakic 1991; Cohen and Servan-Schreiber 1992; Arnsten et al. 1994; Roberts et al. 1994; Williams and Goldman-Rakic 1995; Murphy et al. 1996).

The potential significance of these observations for identifying vulnerable neural circuits in schizophrenia is further illustrated by their apparent specificity. For example, despite the marked developmental changes in the density of the dopamine innervation of DLPFC layer 3, neither the superficial nor the deep cortical layers in the same region (Figure 3) exhibit any significant developmental changes in dopamine innervation (Rosenberg and Lewis 1995). Furthermore, although the dopamine innervation of layer 3 in the entorhinal cortex also exhibits significant developmental changes in density, these changes appear to be completed at a much younger age (Erickson et al. 1995). In particular, the density of dopamine varicosities in the entorhinal cor-

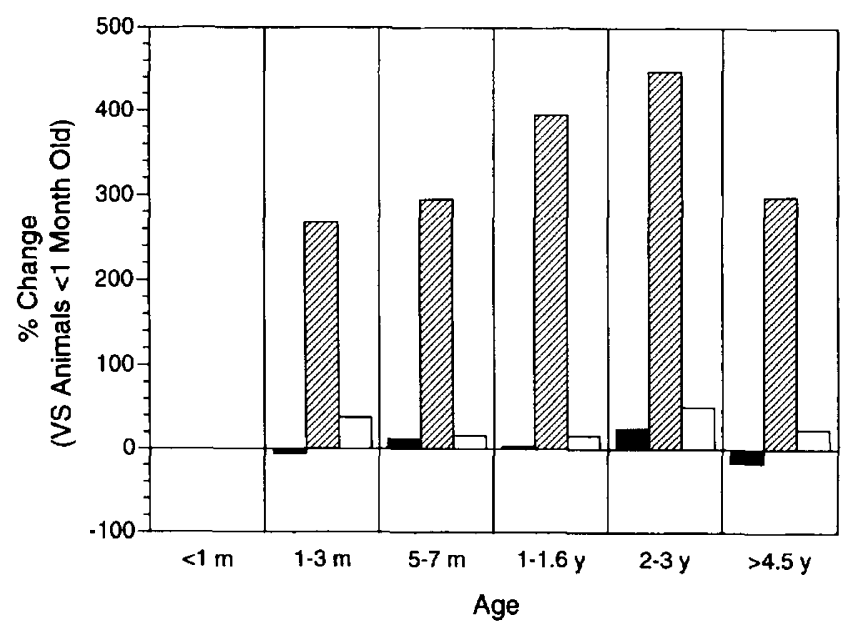

Figure 3. Percentage change (compared to animals less than 1 month of age) in the density of dopamine axon varicosities in three different layers of monkey DLPFC. Note the marked developmental changes in deep layer 3 (cross-hatched bars) and the virtual absence of change in layers 1-2 (solid bars) and deep 6 (open bars). Adapted from Rosenberg and Lewis 1995. tex peaks at around 6 months of age and then quickly declines to stable values that persist throughout adolescence and into adulthood. The results of preliminary studies also suggest that serotonin axons, which may have different synaptic targets from dopamine axons in the monkey PFC (Smiley and Goldman-Rakic 1996), exhibit limited developmental changes during adolescence (Kye et al. 1996).

Finally, in contrast to the synchronous patterns of developmental changes in synaptically linked neural elements of DLPFC layer 3, the density of cholecystokinin (CCK)-positive neurons in layers 1-superficial 3 is most prominent at birth and falls to a constant adultlike level by 1 year of age (Oeth and Lewis 1993). That is, as the densities of dendritic spines, PV-immunoreactive cartridges, and dopamine varicosities increase, the expression of CCK immunoreactivity declines (Figure 4). These CCK-positive cells belong to two classes of local circuit neurons (Oeth and Lewis 1990; Lund and Lewis 1993), narrow arbor neurons connecting layers 2 and 4 , and medium arbor neurons with axons confined to layers 2 and superficial 3 . Although the synaptic targets of these CCK-containing neurons remain to be identified, they appear to have their major targets in layers 2 and 4 , respectively, and to lack a direct influence on neuronal activity in layer 3 . Taken together, these data suggest that there is a high degree of specificity in the postnatal refinement of monkey DLPFC circuitry and thus support the view that those elements that do change during adolescence may be particularly relevant to the pathophysiology of schizophrenia.

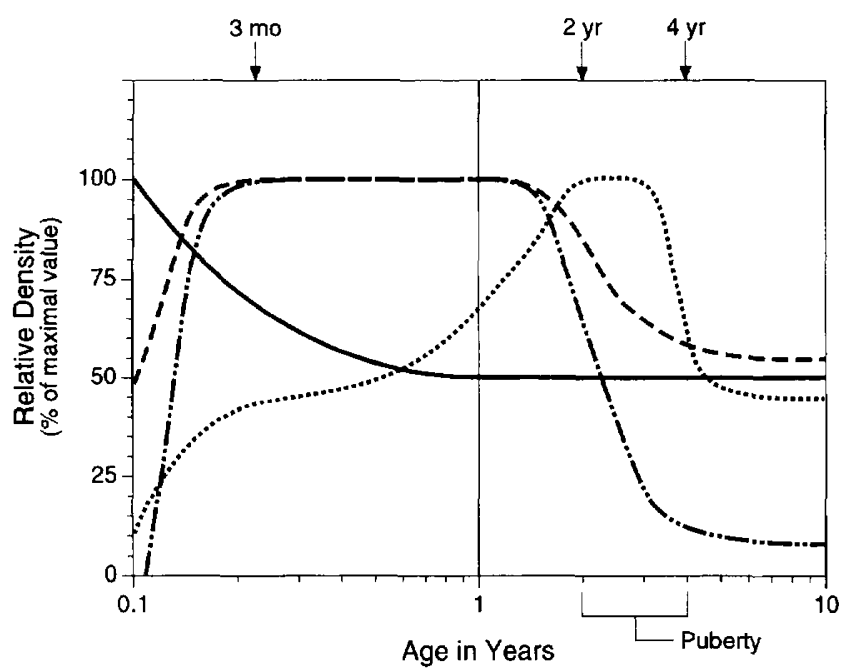

Figure 4. Differential age-related changes in four components of primate DLPFC circuitry, plotted as a percentage of the maximal value for each measure. Broken line, spine density on layer 3 pyramidal neurons; broken line with dots, PVpositive chandelier neuron axon cartridges in layer 3; dotted line, DA varicosities in layer 3; solid line, CCK neurons. See text for details. Adapted from Anderson et al. 1995. 


\section{VULNERABLE DLPFC CIRCUITRY IN SCHIZOPHRENIA}

As summarized in Figure 1, recent studies have shown that DLPFC layer 3 pyramidal neurons, certain classes of local circuit GABA neurons, and dopamine afferents (1) are synaptically-linked; (2) undergo substantial, temporally associated maturational changes during adolescence; and (3) may be critical components of the neural substrate for delayed-response tasks. Thus, given the impairments in delayed-response type tasks exhibited by schizophrenia subjects and the apparent importance of adolescence-related developmental events in the onset of this disorder, these components of DLPFC neural circuitry may be particularly likely to be disturbed in schizophrenia. The results of preliminary studies of postmortem human brain are consistent with this hypothesis. For example, in schizophrenic subjects, mean neuronal size has been reported to be decreased in layer 3, especially in the deep portions of this layer (Rajkowska et al. 1994). In addition, although the number of small and medium neurons was increased by $60 \%$ to $140 \%$ in all cortical layers in schizophrenic subjects, the number of large cells in layer 3 was significantly decreased. These findings suggest that large neurons (which are predominantly pyramidal cells) in layer 3 of the DLPFC have either atrophied or failed to achieve their normal size in schizophrenics, perhaps as a consequence of diminished afferent input. Furthermore, two preliminary reports indicate that the density of dendritic spines on layer 3 pyramidal cells is decreased in schizophrenic subjects (Garey et al. 1995; Glantz and Lewis 1995), an observation consistent with a decreased complement of excitatory synapses on these cells. Whether this abnormality is due to an aberration in the normal decline of these synaptic inputs during adolescence or to a disturbance in synaptogenesis earlier in development cannot be determined from these data. However, in either case, they are consistent with the idea that the number of reciprocal, intrinsic excitatory connections among the stripelike clusters of layer 3 pyramidal neurons in the DLPFC are deficient in schizophrenia and that this circuitry abnormality contributes to the impaired performance on delayed-response tasks seen in schizophrenic subjects. The possible relationships between deficits on these types of tasks and the clinical symptoms of schizophrenia have been discussed elsewhere (Goldman-Rakic 1991; Fuster 1993; Lewis and Anderson 1995).

\section{CONCLUSION}

Although many recent studies have focused on the potential importance of early developmental events in schizophrenia, the question of why the onset of clinical symptoms is delayed until late adolescence or early adulthood remains unanswered. The studies reviewed above demonstrate that substantial refinements occur in the functional architecture of the primate DLFPC during this late developmental period and suggest that these changes may reveal the elements of DLPFC circuitry, namely layer 3 pyramidal neurons and their inputs and axonal targets, that are likely to be involved in the pathophysiology of schizophrenia.

Further understanding of the role of this circuitry in schizophrenia can be obtained from both monkey and human studies. For example, although the studies described above clearly indicate that substantial changes in the functional architecture of the macaque monkey DLPFC occur between the ages of 2 and 4 years, additional animals within this age range need to be studied to determine the precise time course of these changes, their temporal relationship to the process of sexual maturation, and the potential influence of gonadal steroids on refinements in DLPFC circuitry. In addition, it is not known whether the timing of these changes differs between males and females, an observation that may be particularly important given the tendency for females to first manifest the symptoms of schizophrenia at a later age than males (see Castle and Murray 1991 for review).

Although there are obvious difficulties in determining precisely how the timing of the changes in DLPFC circuitry in monkeys correlate with human development, the parallel findings across species in both the anatomical and behavioral studies conducted to date suggest that the period of 2 to 4 years of age in monkeys can be considered analogous to the second decade of human life. As the pathophysiological processes underlying schizophrenia begin before a first hospitalization or first reported experience of psychotic symptoms, developmental changes that occur during the teenage years are likely to be of particular relevance (Haas and Sweeney 1992; Larsen et al. 1996). In addition, although the same sequence of developmental events is likely to occur in each person, the exact timing may differ substantially across individuals, perhaps providing another source for differences among schizophrenic subjects in the age of symptom onset.

The preliminary results of postmortem studies have produced supporting evidence for the hypothesis that the circuitry depicted in Figure 1 is altered in schizophrenia, but additional studies need to be undertaken. In concert with the results of other investigations, a number of specific lines of inquiry can be identified. For example, levels of the mRNA for glutamic acid decarboxylase (GAD), the enzyme that controls GABA synthesis, have been reported to be decreased in the DLPFC of schizophrenic subjects (Akbarian et al. 1995), but whether these changes affect all or only a subpopulation of GABA neurons is not known (Lewis 1995). The 
fact that the PV-containing chandelier class of local circuit GABA neurons preferentially targets pyramidal neurons and undergoes late developmental changes suggests that alterations in GAD expression may be present in these neurons, a hypothesis that is readily testable in postmortem investigations. Consistent with this hypothesis, the density of chandelier neuron axon cartridges immunoreactive for the GABA- 1 transporter appears to be decreased in the DLPFC of schizophrenic subjects (Woo et al. 1996).

It also should be noted that the diagram in Figure 1 does not include other potentially important components of DLPFC circuitry that may be vulnerable in schizophrenia, such as projections from the medial dorsal thalamic nucleus that terminate in cortical layers 4 and deep 3 (Giguere and Goldman-Rakic 1988). Although the synaptic targets of these afferents have not been investigated in primates, they are in position to provide synaptic input to the basilar dendrites of layer 3 pyramidal neurons and/or the PV-containing neurons in these layers. Knowledge of the synaptic targets of the thalamic inputs to the DLPFC and the extent to which the organization of these afferent projections undergoes late developmental changes may be of particular value, especially in light of the reported abnormalities of prefrontal subplate neurons in schizophrenia (Akbarian et al. 1993, 1996; Anderson et al. 1996) and of the critical role played by subplate neurons in the formation of thalamocortical connections (Ghosh et al. 1990). Thus, developmental studies of the thalamic projections to the DLPFC may provide additional insight into the relationship between abnormalities in the thalamus (Pakkenberg 1990; Andreasen et al. 1994a; Buschbaum et al. 1996; Frazier et al. 1996) and the DLPFC in schizophrenia.

\section{ACKNOWLEDGMENTS}

The author thanks Mary Brady for assistance in preparing the figures and Stewart Anderson, Susan Erickson, Jeffrey Hollerman, Darlene Melchitzky, Joseph Pierri, and Tsung-Ung Woo for helpful comments and discussion. Studies by the author cited in this manuscript were supported by USPHS grants MH45156, MH51234, MH43784, and Independent Scientist Award MH00519.

\section{REFERENCES}

Akbarian S, Bunney WE Jr, Potkin SG, Wigal SB, Hagman JO, Sandman CA, Jones EG (1993): Altered distribution of nicotaminide-adenine dinucleotide phosphate-diaphorase cells in frontal lobe of schizophrenics implies disturbances of cortical development. Arch Gen Psychiatr 50:169-177

Akbarian S, Kim JJ, Potkin SG, Hagman JO, Tafazzoli A, Bunney WE Jr, Jones EG (1995): Gene expression for glutamic acid decarboxylase is reduced without loss of neurons in prefrontal cortex of schizophrenics. Arch Gen Psychiatr 52:258-266

Akbarian S, Kim JJ, Potkin SG, Hetrick WP, Bunney Jr WE, Jones EG (1996): Maldistribution of interstertial neurons in prefrontal white matter of the brains of schizophrenic patients. Arch Gen Psychiatr 53:425-436

Akil M, Lewis DA (1992): Differential distribution of parvalbumin-immunoreactive pericellular clusters of terminal boutons in developing and adult monkey neocortex. Exp Neurol 115:239-249

Alexander GE (1982): Functional development of frontal association cortex in monkeys: Behavioral and electrophysiological studies. Neurosci Res Prog Bull 20:471-479

Alexander GE, Goldman PS (1978): Functional development of the dorsolateral prefrontal cortex: An analysis utilizing reversible cryogenic depression. Brain Res 143:233-249

Anderson SA, Classey JD, Condé F, Lund JS, Lewis DA (1995): Synchronous development of pyramidal neuron dendritic spines and parvalbumin-immunoreactive chandelier neuron axon terminals in layer III of monkey prefrontal cortex. Neuroscience 67:7-22

Anderson SA, Volk DW, Lewis DA (1996): Increased density of microtubule associated protein 2-immunoreactive neurons in the prefrontal white matter of schizophrenic subjects. Schiz Res 19:111-119

Andreasen NC, Arndt S, Swayze VII, Cizadlo T, Flaum M, O'Leary D, Ehrhardt JC, Yuh WTC (1994a): Thalamic abnormalities in schizophrenia visualized through magnetic resonance image averaging. Science 266:294-298

Andreasen NC, Flashman L, Flaum M, Arndt S, Swayze VII, O'Leary DS, Ehrhardt JC, Yuh WTC (1994b): Regional brain abnormalities in schizophrenia measured with magnetic resonance imaging. JAMA 272:1763-1769

Arnsten AFT, Cai JX, Murphy BL, Goldman-Rakic PS (1994): Dopamine $D_{1}$ receptors mechanisms in the cognitive performance of young adult and aged monkeys. Psychopharmacology 116:143-151

Barbas H, Pandya DN (1989): Architecture and intrinsic connections of the prefrontal cortex in the rhesus monkey. J Comp Neurol 286:353-375

Bauer RH, Fuster JM (1976): Delayed matching and delayedresponse deficit from cooling dorsolateral prefrontal cortex in monkeys. J Comp Physiol Psychol 90:293-302

Benes FM (1991): Toward a neurodevelopmental understanding of schizophrenia and other psychiatric disorders. In Cicchetti D, Toth SL (eds), Models and Integrations: Rochester Symposium on Developmental Psychopathology, vol 3, Rochester, NY, University of Rochester Press, pp 161-184

Benes FM, McSparren J, Bird ED, SanGiovanni JP, Vincent SL (1991): Deficits in small interneurons in prefrontal and cingulate cortices of schizophrenic and schizoaffective patients. Arch Gen Psychiatr 48:996-1001

Bourgeois J-P, Rakic P (1993): Changes in synaptic density in the primary visual cortex of the macaque monkey from fetal to adult stage. J Neurosci 13:2801-2820

Bourgeois J-P, Goldman-Rakic PS, Rakic P (1994): Synaptogenesis in the prefrontal cortex of rhesus monkeys. Cereb Cortex 4:78-96

Breier A, Buchanan RW, Elkashef A, Munson RC, Kirk- 
patrick B, Gellad F (1992): Brain morphology and schizophrenia: A magnetic resonance imaging study of limbic, prefrontal cortex, and caudate structures. Arch Gen Psychiatr 49:921-926

Brozoski TJ, Brown RM, Rosvold HE, Goldman PS (1979): Cognitive deficit caused by regional depletion of dopamine in prefrontal cortex of rhesus monkeys. Science 205:929-932

Buschbaum MS, Someya T, Teng CY, Abel L, Chin S, Najadi A, Haier RJ, Wu J, Bunney WE Jr (1996): PET and MRI of the thalamus in never-medicated patients with schizophrenia. Am J Psychiatr 153:191-199

Castle DJ, Murray RM (1991): The neurodevelopmental basis of sex differences in schizophrenia. Psychol Med 21:565575

Celio MR (1986): Parvalbumin in most gamma-aminobutyric acid-containing neurons of the rat cerebral cortex. Science 231:995-998

Changeux J-P, Danchin A (1976): Selective stabilization of developing synapses as a mechanism for the specification of neuronal networks. Nature 264:705-712

Chiron C, Raynaud C, Mazière B, Zilbovicus M, Laflamme L, Masure M-C, Dulac O, Bourguignon M, Syrota A (1992): Changes in regional cerebral blood flow during brain maturation in children and adolescents. J Nucl Med 33:696-703

Chua SE, McKenna PJ (1995): Schizophrenia-a brain disease? A critical review of structural and functional abnormality in the disorder. Brit J Psychiatr 166:563-582

Chugani HT, Phelps ME, Mazziotta JC (1987): Positron emission tomography study of human brain functional development. Ann Neurol 22:487-497

Cohen JD, Servan-Schreiber D (1992): Context, cortex, and dopamine: A connectionist approach to behavior and biology in schizophrenia. Psychol Rev 99:45-77

Colonnier M (1968): Synaptic patterns on different cell types in the different laminae of the cat visual cortex. An electron microscope study. Brain Res 9:268-287

Condé F, Lund JS, Jacobowitz DM, Baimbridge KG, Lewis DA (1994): Local circuit neurons immunoreactive for calretinin, calbinin D-28k, or parvalbumin in monkey prefrontal cortex: Distribution and morphology. J Comp Neurol 341:95-116

Condé F, Lund JS, Lewis DA (1996): The hierarchical development of monkey visual cortical regions as revealed by the maturation of parvalbumin-immunoreactive neurons. Dev Brain Res 96:261-276

Daviss SR, Lewis DA (1995): Local circuit neurons of the prefrontal cortex in schizophrenia: Selective increase in the density of calbindin-immunoreactive neurons. Psychiatr Res 59:81-96

DeFelipe J, Hendry SHC, Jones EG, Schmechel D (1985): Variability in the terminations of GABAergic chandelier cell axons on initial segments of pyramidal cell axons in the monkey sensory-motor cortex. J Comp Neurol 231: 364-384

DeFelipe J, Hendry SHC, Jones EG (1989): Visualization of chandelier cell axons by parvalbumin immunoreactivity in monkey cerebral cortex. Proc Natl Acad Sci USA 86:2093-2097
Diamond A (1985): The development of the ability to use recall to guide action, as indicated by infants' performances on AB. Child Devel 56:868-883

Diamond A (1990): Developmental time course in human infants and infant monkeys, and the neural bases of, inhibitory control in reaching. Ann NY Acad Sci 608:637-676

Erickson SL, Akil M, Levey AI, Lewis DA (1995): Postnatal development of the dopaminergic innervation of monkey entorhinal cortex. Soc Neurosci Abstr 21:1134

Feinberg I (1982): Schizophrenia: Caused by a fault in programmed synaptic elimination during adolescence? J Psychiat Res 17:319-334

Frazier JA, Giedd JN, Hamburger SD, Albus KE, Kaysen D, Vaituzis AC, Rajapakse JC, Lenane MC, McKenna K, Jacobsen LK, Gordon CT, Breier A, Rapoport JL (1996): Brain anatomic magnetic resonance imaging in childhood-onset schizophrenia. Arch Gen Psychiatr 53:617-624

Friedman HR, Goldman-Rakic PS (1994): Coactivation of prefrontal cortex and inferior parietal cortex in working memory tasks revealed by 2DG functional mapping in the rhesus monkey. J Neurosci 14:2775-2788

Friston KJ, Frith CD (1995): Schizophrenia: A disconnection? Clin Neurosci 3:89-97

Funahashi S, Bruce CJ, Goldman-Rakic PS (1989): Mnemonic coding of visual space in the monkey's dorsolateral prefrontal cortex. J Neurophysiol 61:331-349

Fuster JM (1989): The Prefrontal Cortex: Anatomy, Physiology and Neuropsychology of the Frontal Lobe. New York, Raven Press

Fuster JM (1993): Frontal lobes. Curr Opin Neurobiol 3:160-165

Fuster JM, Bauer RH, Jervey JP (1982): Cellular discharge in the dorsolateral prefrontal cortex of the monkey in cognitive tasks. Exp Neurol 77:679-694

Garey LJ, Ong WY, Patel TS, Kanani M, Davis C, Hornstein C, Bauer M (1995): Reduction in dendritic spine number on cortical pyramidal neurons in schizophrenia. Soc Neurosci Abstr 21:237

Ghosh A, Antonini A, McConnell SK, Shatz CJ (1990): Requirement for subplate neurons in the formation of thalamocortical connections. Nature 347:179-181

Giguere M, Goldman-Rakic PS (1988): Mediodorsal nucleus: Areal, laminar, and tangential distribution of afferents and efferents in the frontal lobe of rhesus monkeys. J Comp Neurol 277:195-213

Glantz LA, Lewis DA (1995): Assessment of spine density on layer III pyramidal cells in the prefrontal cortex of schizophrenic subjects. Soc Neurosci Abstr 21:239

Glantz LA, Lewis DA (in press): Reduction of synaptophysin immunoreactivity in the prefrontal cortex of schizophrenic subjects: Regional and diagnostic and specificity. Arch Gen Psychiatr

Goldman PS (1971): Functional development of the prefrontal cortex in early life and the problem of neuronal plasticity. Exp Neurol 32:366-387

Goldman PS (1974): An alternative to developmental plasticity: Heterology of CNS structures in infants and adults. In Stein DG, Rosen J, Butters N (eds), CNS Plasticity and Recovery of Function, New York, Academic, pp 149-174 
Goldman PS, Rosvold HE (1972): The effects of selective caudate lesions in infant and juvenile rhesus monkeys. Brain Res 43:53-66

Goldman-Rakic PS (1987a): Circuitry of primate prefrontal cortex and regulation of behavior by representational memory. In Plum F, Mountcastle V (eds), Handbook of Physiology, Bethesda, MD, American Physiological Society, pp 373-417

Goldman-Rakic PS (1987b): Development of cortical circuitry and cognitive function. Child Devel 58:601-622

Goldman-Rakic PS (1991): Prefrontal cortical dysfunction in schizophrenia: The relevance of working memory. In Carroll BJ, Barrett JE (eds), Psychopathology and the Brain, New York, Raven Press, pp 1-23

Goldman-Rakic PS, Brown RM (1982): Postnatal development of monoamine content and synthesis in the cerebral cortex of rhesus monkeys. Dev Brain Res 4:339-349

Goldman-Rakic PS, Leranth C, Williams SM, Mons N, Geffard M (1989): Dopamine synaptic complex with pyramidal neurons in primate cerebral cortex. Proc Natl Acad Sci USA 86:9015-9019

Gur RC, Gur RE (1995): Hypofrontality in schizophrenia: RIP. Lancet 345:1383-1384

Haas GL, Sweeney JA (1992): Premorbid and onset features of first-episode schizophrenia. Schiz Bull 18:373-386

Heizmann CW (1984): Parvalbumin an intracellular calciumbinding protein. Distribution properties and possible roles in mammalian cells. Experientia 40:910-921

Hoffman RE, Dobscha SK (1989): Cortical pruning and the development of schizophrenia: A computer model. Schizophr Bull 15:477-490

Huttenlocher PR (1979): Synaptic density in human frontal cortex-Developmental changes and effects of aging. Brain Res 163:195-205

Huttenlocker PR, DeCourten C (1987): The development of synapses in striate cortex of man. Human Neurobiol 6:1-9

Jones EG (1975): Varieties and distribution of nonpyramidal cells in the somatic sensory cortex of the squirrel monkey. J Comp Neurol 160:205-268

Karson CN, Griffin WS, Mrak RE, Sturner WQ, Shillutt S, Guggenheim FG (1996): Reduced levels of synaptic proteins in the prefrontal cortex in schizophrenia. Soc Neurosci Abstr 22:1677

Kawaguchi Y (1995): Physiological subgroups of nonpyramidal cells with specific morphological characteristics in layer II/III of rate frontal cortex. J Neurosci 15:26382655

Kritzer MF, Goldman-Rakic PS (1995): Intrinsic circuit organization of the major layers and sublayers of the dorsolateral prefrontal cortex in the rhesus monkey. J Comp Neurol 359:131-143

Kye CH, Woo T-U, Lewis DA (1996): Postnatal development of serotonin transporter-immunoreactive axons in monkey prefrontal cortex. Soc Neurosci Abstr 22:905

LaMantia A-S, Rakic P (1990): Axon overproduction and elimination in the corpus callosum of the developing rhesus monkey. J Neurosci 10:2156-2175

Larsen TK, McGlashan TH, Johannessen JO, Vibe-Hansen L
(1996): First-episode schizophrenia: II. Premorbid patterns by gender. Schiz Bull 22:257-269

LeVay S (1973): Synaptic patterns in the visual cortex of the cat and monkey. Electron microscopy of Golgi preparations. J Comp Neurol 150:53-86

Levin HS, Culbane KA, Hartmann J, Evankovich K, Mattson AJ (1991): Developmental changes in performance on tests of purported frontal lobe functioning. Dev Neuropsych 7:377-395

Levin S (1984): Frontal lobe dysfunctions in schizophreniaII. Impairments of psychological and brain functions. J Psychiatr Res 18:57-72

Levitt JB, Lewis DA, Yoshioka T, Lund JS (1993): Topography of pyramidal neuron intrinsic connections in macaque monkey prefrontal cortex (areas $9 \& 46$ ). J Comp Neurol 338:360-376

Lewis DA (1995): Neural circuity of the prefrontal cortex in schizophrenia. Arch Gen Psychiatr 52:269-273

Lewis DA, Anderson SA (1995): The functional architecture of the prefrontal cortex and schizophrenia. Psychol Med 25:887-894

Lewis DA, Harris HW (1991): Differential laminar distribution of tyrosine hydroxylase-immunoreactive axons in infant and adult monkey prefrontal cortex. Neurosci Lett 125:151-154

Lewis DA, Lund JS (1990): Heterogeneity of chandelier neurons in monkey neocortex: Corticotropin-releasing factor and parvalbumin immunoreactive populations. J Comp Neurol 293:599-615

Lidow MS, Goldman-Rakic PS, Rakic P (1991): Synchronized overproduction of neurotransmitter receptors in diverse regions of the primate cerebral cortex. Proc Natl Acad Sci USA 88:10218-10221

Lund JS, Holbach S (1991): Postnatal development of thalamic recipient neurons in monkey striate cortex: I. A comparison of spine acquisition and dendritic growth of layer $4 \mathrm{C}$ alpha and beta spiny stellate neurons. J Comp Neurol 309:115-128

Lund JS, Lewis DA (1993): Local circuit neurons of developing and mature macaque prefrontal cortex: Golgi and immunocytochemical characteristics. J Comp Neurol 328:282-312

Lund JS, Yoshioka T, Levitt JB (1993): Comparison of intrinsic connectivity in different areas of macaque monkey cerebral cortex. Cereb Cortex 3:148-162

Mates SL, Lund JS (1983): Spine formation and maturation of type 1 synapses on spiny stellate neurons in primate visual cortex. J Comp Neurol 221:91-97

Melchitzky DS, Sesack SR, Pucak ML, Lewis DA (1995): Synaptic targets of pyramidal neuron axon collaterals providing horizontal connections in monkey prefrontal cortex. Soc Neurosci Abstr 21:409

Miller EA, Goldman PS, Rosvold HE (1973): Delayed recovery of function following orbital lesions in infant monkeys. Science 182:304-306

Murphy BL, Arnsten AFT, Goldman-Rakic PS, Roth RH (1996): Increased dopamine turnover in the prefrontal cortex impairs spatial working memory performance in rats and monkeys. Proc Natl Acad Sci USA 93:1325-1329

Murray RM, O'Callaghan E, Castle DJ, Lewis SW (1992): A 
neurodevelopmental approach to the classification of schizophrenia. Schiz Bull 18:319-332

Oeth KM, Lewis DA (1990): Cholecystokinin innervation of monkey prefrontal cortex: An immunohistochemical study. J Comp Neurol 301:123-137

Oeth KM, Lewis DA (1993): Postnatal development of the cholecystokinin innervation of monkey prefrontal cortex. J Comp Neurol 336:400-418

Pakkenberg B (1987): Post-mortem study of chronic schizophrenic brains. Br J Psychiatr 151:744-752

Pakkenberg B (1990): Pronounced reduction of nerve cell number in mediodorsal thalamic nucleus accumbens in schizophrenics. Arch Gen Psychiatr 47:1023-1028

Pakkenberg B (1993): Total nerve cell number in neocortex in chronic schizophrenics and controls estimated using optical disectors. Biol Psychiatr 34:768-772

Park S, Holzman PS (1992): Schizophrenics show spatial working memory deficits. Arch Gen Psychiatr 49:975-982

Pearlson GD, Petty RG, Ross CA, Tien AY (1996): Schizophrenia: A disease of heteromodal association cortex? Neuropsychopharmacology 14:1-17

Perrone-Bizzozero NI, Sower AC, Bird ED, Benowitz LI, Ivins KJ, Neve RL (1996): Levels of the growth-associated protein GAP-43 are selectively increased in association cortices in schizophrenia. Proc Natl Acad Sci USA 93:14182-14187

Peters A (1984): Chandelier cells. In Jones EG, Peters A (eds), Cerebral Cortex, vol. 1, New York, Plenum, pp 361-380

Pettegrew JW, Keshavan MS, Panchalingam K, Strychor S, Kaplan DB, Tretta MG, Allen M (1991): Alterations in brain high-energy phosphate and membrane phospholipid metabolism in first-episode, drug-naive schizophrenics. Arch Gen Psychiatr 48:563-568

Pilowksy LS, Kerwin RW, Murray RM (1993): Schizophrenia: A neurodevelopmental perspective. Neuropsychopharmacology 9:83-91

Plant TM (1988): Neuroendocrine basis of puberty in the rhesus monkey (Macaca mulatta). In Martin L, Ganong WF (eds), Frontiers in Neuroendocrinology, vol 10, New York, Raven, pp 215-238

Pucak ML, Levitt JB, Lund JS, Lewis DA (1996): Patterns of intrinsic and associational excitatory circuitry in monkey prefrontal cortex. J Comp Neurol 376:614-630

Purves D, Lichtman JW (1980): Elimination of synapses in the developing nervous system. Science 210:153-157

Rajkowska G, Selemon LD, Goldman-Rakic PS (1994): Reduction in neuronal sizes in prefrontal cortex of schizophrenics and Huntington patients. Soc Neurosci Abstr 20:620

Rakic P, Bourgeois J-P, Eckenhoff MF, Zecevic N, GoldmanRakic PS (1986): Concurrent overproduction of synapses in diverse regions of the primate cerebral cortex. Science 232:232-235

Roberts AC, DeSalvia MA, Wilkinson LS, Collins P, Muir JL, Everitt BJ, Robbins TW (1994): 6-Hydroxydopamine lesions of the prefrontal cortex in monkeys enhance performance on an analog of the Wisconsin Card Sort Test: Possible interactions with subcortical dopamine. J Neurosci 14:2531-2544
Rosenberg DR, Lewis DA (1995): Postnatal maturation of the dopaminergic innervation of monkey prefrontal and motor cortices: A tyrosine hydroxylase immunohistochemical analysis. J Comp Neurol 358:383-400

Saint Marie RL, Peters A (1985): The morphology and synaptic connections of spiny stellate neurons in monkey visual cortex (area 17): A Golgi-electron microscopic study. J Comp Neurol 233:213-235

Sawaguchi T, Matsumura M, Kubota K (1986): Dopamine modulates neuronal activities related to motor performance in the monkey prefrontal cortex. Brain Res $371: 404-408$

Sawaguchi T, Goldman-Rakic PS (1991): $\mathrm{D}_{1}$ dopamine receptors in prefrontal cortex: Involvement in working memory. Science 251:947-950

Schlaepfer TE, Harris GJ, Tien AY, Peng LW, Lee S, Federman EB, Chase GA, Barta PE, Pearlson GD (1994): Decreased regional cortical gray matter volume in schizophrenia. Am J Psychiatr 151:842-848

Schwartz ML, Goldman-Rakic PS (1984): Callosal and intrahemispheric connectivity of the prefrontal association cortex in rhesus monkey: Relation between intraparietal and principal sulcal cortex. J Comp Neurol 226:403-420

Selemon LD, Rajkowska G, Goldman-Rakic PS (1995): Abnormally high neuronal density in the schizophrenic cortex: A morphometric analysis of prefrontal area 9 and occipital area 17. Arch Gen Psychiatr 52:805-818

Sesack SR, Bressler CN, Lewis DA (1995a): Ultrastructural associations between dopamine terminals and local circuit neurons in the monkey prefrontal cortex: A study of calretinin-immunoreactive cells. Neurosci Lett 200:9-12

Sesack SR, Snyder CL, Lewis DA (1995b): Axon terminals immunolabeled for dopamine or tyrosine hydroxylase synapse on GABA-immunoreactive dendrites in rat and monkey cortex. J Comp Neurol 363:264-280

Shelton RC, Karson CN, Doran AR, Pickar D, Bigelow LB, Weinberger DR (1988): Cerebral structural pathology in schizophrenia: Evidence for a selective prefrontal cortical defect. Am J Psychiatr 145:154-163

Smiley JF, Goldman-Rakic PS (1993): Heterogeneous targets of dopamine synapses in monkey prefrontal cortex demonstrated by serial section electron microscopy: A laminar analysis using the silver-enhanced diaminobenzidine sulfide (SEDS) immunolabeling technique. Cereb Cortex 3:223-238

Smiley JF, Goldman-Rakic PS (1996): Serotonergic axons in monkey prefrontal cerebral cortex synapse predominantly on interneurons as demonstrated by serial section electron microscopy. J Comp Neurol 367:431-443

Smiley JF, Williams SM, Szigeti K, Goldman-Rakic PS (1992): Light and electron microscopic characterization of dopamine-immunoreactive axons in human cerebral cortex. J Comp Neurol 321:325-335

Somogyi P (1977): A specific axo-axonal interneuron in the visual cortex of the rat. Brain Res 136:345-350

Stanley JA, Williamson PC, Drost DJ, Carr TJ, Rylett RJ, Malla A, Thompson RT (1995): An in vivo study of the prefrontal cortex of schizophrenic patients at different stages of illness via phosphorus magnetic resonance spectroscopy. Arch Gen Psychiatr 52:399-406 
Szentagothai J, Arbib M (1974): Conceptual models of neural organization. Neurosci Res Program Bull 12:307-510

Szymanski S, Lieberman JA, Alvi JM, Mayerhoff D, Loebel A, Geisler A, Chakos M, Koreen A, Jody D, Kane J, Woerner M, Cooper T (1995): Gender differences in onset of illness, treatment response, course, and biological indexes in first-episode schizophrenic patients. Am J Psychiatr 152:698-703

Waddington JL (1993): Schizophrenia: Developmental neuroscience and pathobiology. Lancet 341:531-536

Weinberger DR (1987): Implications of normal brain development for the pathogenesis of schizophrenia. Arch Gen Psychiatr 44:660-669

Weinberger DR, Berman KF, Zec RF (1986): Physiologic dysfunction of dorsolateral prefrontal cortex in schizophrenia. I. Regional cerebral blood flow evidence. Arch Gen Psychiatr 43:114-124

Wible CG, Shenton ME, Hokama H, Kikinis R, Jolesz FA,
Metcalf D, McCarley RW (1995): Prefrontal cortex and schizophrenia. Arch Gen Psychiatr 52:279-288

Williams GV, Goldman-Rakic PS (1995): Modulation of memory fields by dopamine $\mathrm{D}_{1}$ receptors in prefrontal cortex. Nature 376:572-575

Williams SM, Goldman-Rakic PS, Leranth C (1992): The synaptology of parvalbumin-immunoreactive neurons in primate prefrontal cortex. J Comp Neurol 320:353-369

Woo T-U, Pucak ML, Kye CH, Matus CV, Lewis DA (in press): Peripubertal refinement of the intrinsic and associational circuitry in monkey prefrontal cortex. Neuroscience

Woo T-U, Whitehead RE, Lewis DA (1996) Axon terminal cartridges of chandelier neurons in the prefrontal cortex in schizophrenia. Soc Neurosci Abstr 22:1679

Zipursky RB, Lim KO, Sullivan EV, Brown BW, Pfefferbaum A (1992): Widespread cerebral gray matter volume deficits in schizophrenia. Arch Gen Psychiatr 49:195-205 